\title{
A modernização e o processo de urbanização a partir do século XIX: ecos da dominação européia no Brasil e em África.
}

\author{
Guadalupe Estrelita dos Santos Menta ${ }^{1}$
}

RESUMO: O contexto do século XIX marca o acelerado ritmo da modernização e o conseqüente processo de urbanização das grandes cidades, concentrando riquezas e acentuando as diferenças entre classes. A hegemonia cultural européia no Brasil e em várias partes do mundo refletem na economia e nas relações humanas na sociedade e no trabalho. O Cortiço, de Aluísio Azevedo, no Brasil, e em África, Luuanda, de Luandino Vieira, na Estória da galinha e do ovo, salientam a imposição cultural européia.

ABSTRACT: The context of the nineteenth century marks the accelerated pace of modernization and the consequent process of large cities urbanization, concentrating wealths and accentuating the differences among classes. The European cultural hegemony in Brazil and around the world, reflects on the economy and on human relations in society and the labour. $O$ Cortiço, by Aluísio Azevedo, in Brazil, and Africa, Luuanda, by Luandino Vieira, in Estória da galinha e do ovo, emphasizing the European cultural imposition.

PALAVRAS-CHAVE: Modernização; Urbanização; Exploração

KEYWORDS: Modernization; Urbanization; Exploitation

O século XIX foi palco de mudanças na estrutura social, econômica e política em várias partes do globo, devido à Revolução Industrial que impulsionava o capitalismo, fazendo surgir os grandes centros industrias, aglomerando pessoas, grupos operários, que inchavam as cidades, em busca de emprego, mas que não dispunham de boas condições de vida e de dignidade. Com a industrialização, as

1 Doutoranda pela Universidade Estadual de Londrina (UEL). Pesquisa: O universo simbólico de raízes africanas: um olhar sobre a presença do imaginário na memória coletiva dos negros. e-mail: guadalupe.estrelita@hotmail.com 
idéias cientificistas explodem, influenciando profundamente a literatura da época, embasada na retratação da realidade objetiva, com descrições de cenas e valorizando os aspectos "humanos" da coletividade.

Durante o século XIX, uma tradição de pensamento conhecida pelo nome de "Culture and Society" emerge na Grã-Bretanha, impulsionada pelas figuras intelectuais do humanismo romântico. Para além de suas divisões ideológicas, essas figuras têm em comum o fato de denunciarem os estragos da "vida mecanizada", como efeito da "civilização moderna" (MATTELART, 2004, p. 19).

O Naturalismo, no Brasil, corrente literária fundamentada sobretudo na ciência, reflete as mudanças ocorridas no século XIX, sobretudo no que se refere ao "branqueamento" e desnivelamento social. Segundo Bonnici e Zolin (2005, p. 229), no século XIX,o “ estigma da inferioridade cultural e do racismo impregnou também os colonos brancos que, aos olhos dos agentes governamentais e da metrópole ficaram degenerados pelo hibridismo.”A análise do homem enquanto ser, regido pelos instintos, e por componentes hereditários e sociais, movido por ações determinadas pelo meio e pelo momento, como bem retratado em $O$ Cortiço, obra do Naturalismo brasileiro, levantou aspectos relevantes das mazelas sociais e humanas. Essa retratação, por vezes ainda um tanto preconceituosa, devido à zoomorfização do homem, principalmente o negro e o mestiço, bem como às descrições feitas de modo exótico, relegando o "diferente" ao medonho, grotesco, promíscuo, sendo a cultura dos negros, oriunda da África, reduzida ao primitivismo e à superficialidade. Bonnici e Zolin (2005, p. 229), a respeito da mestiçagem no Naturalismo brasileiro, dizem que:

No romance $O$ Cortiço (1890), Jerônimo, o português exemplar, mergulha a massa humana da favela e degrada-se diante dos encantos do ambiente, da música tropical e, de modo especial, da sensualidade de Rita Baiana. A metrópole, portanto, enfatizava o fato de que esses colonos degenerados, prescindindo da herança cultural de seus antepassados europeus, desenvolveram as características dos nativos (preguiça, dança) ou generalizaram aspectos de sua tipicidade nacional (a bebedeira dos irlandeses). 
Todos esses aspectos criaram um sistema mundial no qual certas culturas e sociedades eram consideradas essencialmente inferiores.

Segundo Mattelart (2004, p. 17), “O século XIX instaura o conceito canônico de cultura e a disciplina que a toma como objeto, a antropologia cultural ou etnologia.” Em se tratando de cultura esta é, em suma, um conjunto de saberes: na dança, na religião, no folclore, nas crenças, na arte, etc. Todo povo tem sua cultura, e sem fugir à regra, a África, sendo um continente cuja colonização se deu por diversos fatores e diferentes povos, é plural em termos de língua e cultura em geral. As várias nações africanas, muitas delas rivais, vivem por muito tempo em um uníssono grito de guerra e paz, revolta e liberdade. Segundo Mattelart (2004, p.19), "O conceito de cultura se torna a pedra de toque de uma filosofia política e moral. A literatura se torna seu símbolo e vetor. A freqüentação das obras tidas como capaz de modificar o horizonte de sensibilidade de uma sociedade presa à ideologia do 'feito'”.

O século XIX, também marcado pelo Nacionalismo, segundo Bonnici e Zolin (2005), sobretudo no Brasil, traz seus heróis para o fortalecimento da identidade nacional, heróis estes representados pelos índios, no Romantismo, completamente idealizados e folclorizados. E o negro? Como era retratado? Nesse período, a literatura pouco se referia aos negros e quando o fazia, referia-se a eles como escravos, reforçando um rótulo que marca até hoje pela discriminação e exclusão. No Realismo e Naturalismo, os negros e mestiços tornam-se figuras recorrentes, mas zoomorfizados e relegados ao exótico. Bernt (1988, p. 57) faz uma análise da inserção do negro na literatura, concluindo que "Castro Alves não entrou na pele do negro para ser seu porta-voz, mas que apenas tomou o escravo e a escravidão como temática de eleição quase que por força do momento histórico em que vivia não visa, de modo algum, desfazer seu valor estético, nem sua importância social”.

Esse quadro se repete em vários momentos, pois os povos africanos foram forçados a se descaracterizar, devido à colonização. O 
sistema colonial, opressor e explorador, separou famílias, proibiu o culto às crenças, a dança, o ritmo, o tambor, a língua, tudo em prol de uma imposição cultural, que se julgou superior, sufocando inúmeras outras culturas, consideradas primitivas. Permeando a África de colonização portuguesa, com ênfase em Angola, percebe-se a árdua trajetória dos negros, com infinitas tentativas para buscar a identidade que lhes fora roubada durante o período colonial.

Tanto em solo africano quanto no Brasil, o homem negro foi submetido aos desmandos da cultura de raiz européia, principalmente, relegando-o à condição de sub-raça, transmitindo esse legado às suas gerações, que, mesmo com muita superação, ainda se deparam com a exclusão, oriunda de um racismo e preconceito mascarados, mas nitidamente presentes. Desde a descoberta do Brasil, quando começou o tráfico de escravos, o negro, principal mercadoria destinada à venda para executar trabalhos forçados, ficou à mercê de todo tipo de humilhação e exploração: moral, física, sexual, dentre outras.

Com a Abolição da Escravatura, partindo das idéias da nova mentalidade de influência européia, com o fim da Monarquia e início da República, no que tange ao Brasil, principalmente às metrópoles, o negro recém-liberto, sem instrução escolar, acostumado à relação servil (senhor/escravo), torna-se obsoleto na sociedade, pois não se ajusta às reais necessidades da demanda profissional. Suas qualificações são ínfimas perante uma realidade de industrialização, modernização, onde a tecnologia e as novas técnicas de produção exigem um certo conhecimento formal, priorizando, mais uma vez, o homem branco no mercado de trabalho, principalmente os imigrantes italianos, alemães, franceses, que vieram em busca de oportunidade nas terras brasileiras, cujos conhecimentos se moldavam à realidade industrial e capitalista. Mesmo no trabalho do campo, as técnicas de plantio e de produção em geral, exigiam novos mecanismos, alheios aos negros recém-libertos.

Com a urbanização e a reforma das cidades, sobretudo no Rio de Janeiro, o negro é colocado à margem da sociedade, sendo "empurrado" às periferias, formando as conhecidas favelas. Segundo Moura (1983), o 
mercado de trabalho não absorvia o negro a contento, levando-o, muitas vezes, a tornar-se mendigo, bêbado, marginal e até mesmo suicida, pela dignidade e humanidade que lhe eram negadas. Sobrava-lhe os subempregos - havia os que viviam de expedientes, "biscates" e os que trabalhavam no cais do porto e no Exército, devido à força física. As mulheres, quase sempre as protagonistas das estórias africanas, por serem grandes batalhadoras, eram as heroínas de forno e fogão, e de cama e colchão: exploradas não só como empregadas de fundo de quintal como também objeto sexual, muitas optando pela prostituição para sobreviverem, devido à falta de oportunidades.

O quadro de opressão relatado no Brasil não é tão diferente da História da África Portuguesa. No que se refere a Angola, por muito tempo colônia de Portugal, independente a partir de 1975, vem, a duras penas, montando o quebra-cabeças de sua cultura, esfacelada pelo sistema colonial. A miséria e o descaso com o povo são elementos retratados pelos autores mais compromissados. O povo angolano, além de não poder falar sua língua, foi cerceado do direito de expressar-se culturalmente.

Nos textos africanos contidos em Luuanda, de Luandino Vieira, a relação colonizador-colonizado é retratada de modo crítico e irônico, por vezes recuperando, de modo dialógico, a língua do povo (O Kimbundo) e a oralidade, típica dos povos africanos, por muito tempo ágrafos. Estes elementos que entrelaçam os fatos narrados à literariedade, por meio de um trabalho estético, elaborado, junto ao compromisso social, leva o público leitor à uma recepção crítica e reflexiva.

Ao comparar-se, por exemplo, O Cortiço, de Aluísio Azevedo, com Luuanda, de Luandino Vieira, percebe-se, sobretudo o papel do colonizador aliado à opressão e à exploração do homem negro, visto como objeto, desumanizado, zoomorfizado, exótico e primitivo, elementos que reforçam a ideologia dominante e a discriminação.

Em O Cortiço, o determinismo das personagens os leva à aproximação com animais irracionais, movidos pelos instintos; o representante do poder aquisitivo é o branco, de origem européia, que 
explora a mão-de-obra dos negros, objetos de trabalho e de prazer. O espaço da narrativa, como o próprio título revela, são as favelas, microcosmo de toda promiscuidade, marginalidade e descaso relegado ao homem negro, sobretudo no quadro histórico-social do século XIX e XX, palco da urbanização e imposição da cultura européia.

Como a principal obra do Naturalismo no Brasil, $O$ Cortiço caracteriza-se principalmente pelo aspecto experimental nela desenvolvido, retratando o homem sob o prisma da sua relação com o meio, e produto da hereditariedade. O autor não procura descrever o psicológico como no Realismo, mas sim, as ações do homem sobre o meio e vice-versa.

Em se tratando da mulher negra, em $O$ Cortiço, o autor traz a figura da mulata, exótica e extremamente sensual, com a vulgaridade típica da marginalização e discriminação. "Os meneios da mestiça melhor se acentuavam, cheios de uma graça irresistivel, simples, feita toda de pecado, toda de paraíso, com muito de serpente e muito de mulher" (AZEVEDO, 1998, p. 77).

O sexo é força mais degradante que a ambição e a cobiça. A supervalorização do sexo, típica do determinismo biológico, e do naturalismo, conduz Aluísio a buscar quase todas as formas de patologia sexual, desde o "acanalhamento" das relações matrimoniais, adultério, prostituição, lesbianismo, etc.

Embora as descrições feitas de Rita Baiana pareçam um tanto poéticas, até mesmo dialogando com as descrições comparativas de Alencar a Iracema, fica nítida a intenção dos instintos e da zoomorfização da personagem, aproximada a animais peçonhentos e urticantes, como serpente, muriçoca, que aguçam simbolicamente os desejos sexuais. Até mesmo a referência ao perfume, baunilha, é um fator determinante ao despertar dos desejos, o cheiro como se fossem os feromônios, exalados pela fêmea no cio que atrai o macho para o acasalamento.

A voracidade do capitalismo e as relações de interesses movidas pelo contexto da modernização e urbanização, relegam o homem ao seu 
estado mais primitivo, regido pela lei da seleção natural, do determinismo e do positivismo, em que seu olhar deve ser lançado ao mundo com objetividade: o homem superior se sobrepõe ao inferior, sendo o meio, a raça e o momento responsáveis pelas características de seus descendentes. Num momento onde o desenvolvimento se acelera, a essência do ser humano parece sofrer o efeito contrário, perdendo-se na frieza das relações capitalistas. O sexo e a figura da mulher como objeto sexual demonstram a aproximação do homem com seus instintos mais primitivos, dominado por uma realidade privada de emoções e de sensibilidade, o que reforça o caráter auto-desconstrutor da raça humana.

A referência à escravidão como uma deficiência social marca o enredo, como uma questão polêmica, revelando a exploração do homem pelo homem.

[...] A escrava passara naturalmente em herança a qualquer dos filhos do morto; mas, por estes, nada havia que recear: dois pândegos de marca maior que, empolgada e legitima, cuidariam de tudo, menos de atirar-se na pista de uma crioula a quem não viam[...] (AZEVEDO, 1998, p. 17).

Em Luuanda, o cenário também se passa no musseque, em meio à miséria, confusões e tragédias. Em se tratando de funções, a literatura africana, sobretudo a pós-colonial, traz em si ecos da colonização e suas conseqüências para o povo, submetido à opressão, silenciado, porém, resistente. No livro Luuanda, as estórias que Luandino Vieira retrata com uma mescla de criticidade e de ironia cômica, trazem à tona questões que levam o público leitor a refletir sobre as seqüelas do sistema colonial: há uma tensão entre o povo e o dominador, uma constante dicotomia colonizador/colonizado e uma esperança nas novas idéias com a Independência, período também turbulento devido à disputa do poder.

Problemas de dependência, subdesenvolvimento e marginalização, típicos do 'alto' período colonial, persistem no pós-colonial. Contudo, essas relações estão resumidas em uma 
nova configuração. No passado, eram articuladas como relações desiguais de poder e exploração entre as sociedades colonizadoras e as colonizadas. Atualmente, essas relações são deslocadas e reencarnadas como lutas entre forças sociais nativas, como contradições internas e fontes de desestabilização no interior da sociedade descolonizada, ou entre ela e o sistema global como um todo (HALL, 2006, p. 54)

Este confronto entre africano e europeu, negro e branco, encontra-se tanto no nível temático como no formal. Aspectos lingüísticos e estéticos se contrapõem à forte presença do discurso dominante. Sobretudo na Estória da Galinha e do Ovo, Luandino Vieira retrata o impasse ideológico da posse de um ovo entre duas vizinhas. $\mathrm{O}$ dilema de uma comunidade para fazer a justiça imperar. A estória toda se passa no musseque Sambizanga, local de população pobre, onde os reflexos do sistema colonial, impiedoso e opressor, encontram-se na temática central da narrativa: a disputa por um ovo, ou seja, a luta pela sobrevivência, espelho de toda miséria e descaso a que o povo humilde fora relegado. As marcas da africanidade tanto no discurso quanto na construção formal, salientam um engajamento, que desmonta a estrutura tradicional do conto. Observa-se a aproximação entre História Oficial e a ficção, abrindo possibilidades para que o público as questione. Elementos ligados à força da natureza, que por meio da personificação, anunciam a atmosfera que o tema irá criar na narrativa, são recorrentes nas obras africanas, por fazerem parte de sua cultura.

Assim como, às vezes, dos lados onde o sol fimba no mar, uma pequena e gorda nuvem negra aparece para correr no céu azul e, na corrida, começa a ficar grande, a estender braços para todos os lados, esses braços a ficarem outros braços e esses ainda outros mais finos, já não tão negros, e todo esse apressado caminhar da nuvem no céu parece ramos de muitas folhas de uma mulemba velha, com barbas e tudo, as folhas de muitas cores, algumas secas com o colorido que o sol thes põe e, no fim mesmo, já ninguém que sabe como nasceram, onde começaram, onde acabam, essas malucas filhas da nuvem correndo sobre a cidade, largando água pesada e quente que traziam, rindo compridos e tortos relâmpagos, falando a voz grossa de seus trovões, assim, nessa tarde calma, começou a confusão (VIEIRA, 1982, p. 99). 
No que se refere ao contexto colonial, a figura da prisão é outra constante, o que revela o autoritarismo desmedido da força policial, cujos critérios para o encarceramento eram questionáveis. Como se observa nas palavras de Miguel (VIEIRA,1982, p.100): “- Deixa, Zefa, pópilas! - apaziguava Miguel. - A senhora está concebida então, homem dela preso e você ainda a pelejar? Não tens razão!”. O discurso do colonizado e do colonizador se fundem em uma linguagem híbrida, literariamente elaborada, havendo uma tensão entre ambos. O vozerio inserido na Estória da galinha e do ovo, revela o discurso dos representantes das várias classes sociais e políticas, bem como a voz do povo, que embora silenciada na História Oficial, é salientada por Luandino Vieira, através da construção estética. A inserção de vocábulos africanos, que necessitam de tradução para serem compreendidos, os parágrafos longos, as onomatopéias, a oralidade são marcas da literariedade que tornam as estórias de Luuanda um forte brado crítico à repressão colonial e uma chamada à resistência africana e imposição de sua cultura. A oralidade, por remeter às narrativas tradicionais, "o contar histórias", revela, por meio da memória coletiva, lendas, mitos, tradições, crenças e outros elementos culturais que retomam ideais e as raízes do povo.

Investigar a oralidade manifesta em textos recolhidos da oralidade implica considerar seus traços gerais e fundantes. Formas de pensar, marca textual, gênero discursivo, intertexto: várias são as possiilidades ao se estudar textos colhidos em África que traduzem uma presença da voz que se quer atualizar. Mais ainda, a nosso ver, trazem temas e procedimentos que, junto a essa voz, constituem uma poética particular (TETTAMANZY, 2007, p. 143)

Outro ponto em destaque na Estória da galinha e do ovo é a ancestralidade, que sempre representou a voz da sabedoria, mas aqui parece não dar conta do dilema, recorrendo às várias "autoridades", perdendo terreno para a astúcia do mais jovem, representante das novas idéias sociais e políticas que se pretendiam para o novo momento em Angola. A esperteza, a sagacidade, a esperança no resgate da vida, 
na estória em análise, simbolicamente são expressas pela figura do ovo e da barriga de Nga Bina.

No estatuto colonial, uma relação se coloca como principal e permanente: a de exploração/ dominação e opressão/ repressão do colonizador sobre o colonizado. Mas a idéia de relação impede o pensamento numa só direção, e se existem a opressão e a dominação como principal e permanente em um dos pólos, no outro os principais e permanentes são a libertação e a emancipação, assumidas pelo colonizador como infidelidades e inconfidências (LOPES, 1985, p. 32).

A África, com a escravidão e o sistema colonial vê sua cultura "esfacelada", havendo proibições de seus cultos religiosos, seus ritmos musicais, seus batuques, bem como a língua própria de cada nação, substituída pela língua oficial do colonizador.

Nas jovens literaturas dos países africanos que foram colônias portuguesas o impasse é grande. É incômoda, porém assumida como necessária a opção pela língua portuguesa, bem como é incômoda a assunção da escrita em países cujas populações autóctones possuem culturas complexas, amparadas na oralidade, nas vivências coletivas próprias do mundo rural e da religiosidade animista (TETTAMANZY, 2007, p. 142).

Em Luuanda, na Estória da galinha e do ovo, Luandino Vieira abre a narrativa com a seguinte dedicatória: "Para Amorim e sua gnoma: sonoros corações da nossa terra.9", fazendo referência ao som do tambor, instrumento utilizado não só para a música e ritmos dançantes, mas também como um meio de comunicação entre estes povos, por muito tempo ágrafos, que têm no sangue a musicalidade. A trama toda segue uma linha contínua de dilemas, pois cada um que interfere no caso, quer tirar proveito da situação. Todos os representantes do poder aparecem na narrativa como exploradores: o comerciante português, descrito com tom caricatural; o representante do clero, demagogo e aproveitador; o burguês angolano, capitalista; a burocracia, com caráter duvidoso; e a polícia, autoritária e tendenciosa. A solução fica entre a ancestralidade (as raízes africanas, já sufocadas 
pelo sistema colonial), e a juventude (mudança, as novas idéias, capazes de ações inusitadas a ponto de suplantar a força policial).

Em Luuanda, sociedade em de-vir, ou em processo, de simbiose ou de influências, onde traços de culturas se atritam e disputam primazias, a chamada central do texto parece ser, pois, para o 'esprit de corps' africano de cuja resistência dependerá sua sobrevivência no vir-a-ser de uma identidade em definição (SANTILLI, 1985, p. 82)

Os personagens que figuram o povo, humildes e miseráveis, buscam soluções tanto em suas raízes como no sistema vigente, sedentos de justiça e de harmonia, mas ambos não conseguem restabelecer a paz, ao contrário, estimulam a confusão, prevalecendo portanto as novas idéias, com o bom-senso, que desperta a esperança em povos mais unidos, em busca de sua identidade.

Tanto em África como no Brasil, o século XIX refletiu o quadro desolador das influências colonialistas: a primeira, por ainda viver a realidade de ser colônia, o segundo, por absorver a cultura européia, num período de transição entre Monarquia e República, "fechando os olhos" para a realidade de seu povo, maioria de negros e mestiços, em busca de sua identidade e dignidade humana.

Referências Bibliográficas

AZEVEDO, Aluísio. O Cortiço. 3. ed. São Paulo: FTD, 1998 (Coleção Grandes Leituras).

BERND, Zilá. Introdução à Literatura Negra. São Paulo: Brasiliense, 1988.

BONNICI, Thomas; ZOLIN, Lúcia Osana. Teoria Literária: abordagens históricas e tendências contemporâneas. 2. ed. rev. e ampl. Maringá: EDUEM, 2005.

HALL, Stuart. Da diáspora: identidades e mediações culturais. Liv Sovik (org.). Trad. Adelaine La Guardiã Resende et al. Belo Horizonte/Brasília: UFMG/Unesco, 2006.

LOPES, Eliane Marta Sanches Teixeira. Colonizador - Colonizado: uma relação educativa no movimento da História. Belo Horizonte: UFMG, 1985.

MATTELART, Armand. Diversidade cultural e mundialização. Trad. Marcos Marcionilo. São Paulo: Parábola, 2005. 
MOURA, Roberto.Tia Ciata e a pequena África no Rio de Janeiro. Rio de Janeiro: FUNARTE, 1983.

SANTILLI, Maria Aparecida. Africanidade. São Paulo: Ática, 1985.

TETTAMANZY, Ana Lúcia Liberato. Corpo e voz nas narrativas orais angolanas e moçambicanas. In: Oralidade e Literatura 3: outras veredas da voz. Eudes Fernando Leite e Frederico Fernandes (org.). Londrina: EDUEL, 2007. 139-151.

VIEIRA, Luandino. Estória da galinha e do ovo. In: Luuanda. São Paulo: Ática, 1982. 99-123. 